ACTA UNIVERSITATIS WRATISLAVIENSIS No 3928

Slavica Wratislaviensia CLXXI • Wrocław 2020

DOI: $10.19195 / 0137-1150.171 .9$

Data przesłania artykułu: 17.09.2018

Data akceptacji artykułu: 16.02.2019

HENRYK JAROSZEWICZ

Uniwersytet Wrocławski, Polska

\title{
Współczesny rozwój etnolektu śląskiego na tle językowych procesów emancypacyjnych w Europie
}

1. Przełom XX i XXI wieku bez wątpienia jest w historii lingwistyki wyjątkowym okresem, który można nazwać „wiosną języków”. W stosunkowo krótkim czasie mapa Europy wzbogacona została bowiem o kilkadziesiąt nowych języków, co sprawiło, że dotychczas przyjmowana i utrwalona wieloletnią tradycją klasyfikacja genetyczno-historyczna języków straciła swoją aktualność ${ }^{1}$. Podatny grunt pod tak dynamiczny proces rodzenia się nowych języków przygotowała Unia Europejska swoją polityką wspierania regionów i afirmacji kultur regionalnych, współgrającą zresztą z coraz wyraźniej dostrzegalnymi dążeniami licznych mniejszości etnicznych i językowych do uzyskania podmiotowości i autonomii. Istotny wpływ na wytworzenie się atmosfery sprzyjającej językowej emancypacji miała też liberalizacja życia politycznego w krajach postkomunistycznych oraz pojawienie się w obrębie południowej Słowiańszczyzny wyjątkowo mocnych dążeń do narodowej homogenizacji i państwowej samodzielności.

1.1. Bezpośrednio na rozszerzenie repertuaru języków Europy o nowe jednostki wpłynęły jednak dwa istotne wydarzenia polityczno-społeczne w latach dziewięćdziesiątych XX wieku. Pierwsze z nich miało zasięg ogólnoeuropejski i skutkowało poszerzeniem składu wielu rodzin językowych funkcjonujących na Starym Kontynencie. Mowa tu o przyjęciu w 1992 roku przez Radę Europy Europejskiej karty języków regionalnych lub mniejszościowych, wprowadzającej w swoim tekście kategorię języka regionalnego oraz języka mniejszościowego. Pod tymi pojęciami rozumiano etnolekty, które są tradycyjnie używane na terytorium określonego państwa przez część jego obywateli (będących mniejszością),

${ }^{1}$ Por. A. Czesak, Współczesne teksty ślaskie na tle procesów językotwórczych i standaryzacyjnych współczesnej stowiańszczyzny, Kraków 2015, s. 199-200. 
różnią się jednak od oficjalnego języka państwowego i nie są jego dialektami ${ }^{2}$. Uchwalenie i ratyfikowanie wspomnianego dokumentu spowodowało w licznych państwach rozpoczęcie działan standaryzacyjnych i rewitalizacyjnych oraz podniesienie do rangi języka — regionalnego lub mniejszościowego — wielu etnolektów, które do niedawna zwykle klasyfikowano jako niesamodzielne, podrzędne wobec innych języków dialekty czy gwary. Wśród najbardziej znanych kodów, które na mocy wspomnianego dokumentu uzyskały językowy status, wymienić można: należące do języków germańskich scots (Szkocja i Irlandia Północna), limburski (Holandia), dolnoniemiecki (Niemcy); należące do języków romańskich sardyński (Włochy), friulski (Włochy), galicyjski (Hiszpania), mirandyjski (Portugalia); należące do języków ugrofińskich kweński (Norwegia), võro (Estonia), liwski (Łotwa). Rodzinę języków słowiańskich do tej pory powiększyły jedynie dwa języki - mniejszościowy język łemkowski (rusinsky jazyk na Słowacji, русинська мова na Ukrainie) oraz regionalny język kaszubski.

1.2. Drugie z wydarzeń, które bezpośrednio wpłynęło na powiększenie zasobu języków używanych w Europie, było wyraźnie ograniczone zarówno na płaszczyźnie terytorialnej, jak i językowo-typologicznej. Dotyczyło bowiem wąskiego wycinka środkowych Bałkanów i skutkowało koniecznością modyfikacji składu zaledwie jednej podrodziny językowej. Mowa tu o rozciągniętej na kilkanaście lat dezintegracji multinarodowych jugosłowiańskich i postjugosłowiańskich organizmów państwowych, która skutkowała wykształceniem się czterech nowych samodzielnych języków narodowych: serbskiego, chorwackiego i bośniackiego, a potem także czarnogórskiego. Jak powszechnie wiadomo, kodom tym jeszcze do początku lat dziewięćdziesiątych dość powszechnie odmawiano samodzielności, uznając je za regionalno-narodowe odmiany jednego, wspólnego języka - serbsko-chorwackiego ${ }^{3}$.

Choć schyłek ubiegłego wieku i początek niniejszego to okres szczególnie sprzyjający procesom językowej emancypacji, warto zauważyć, że pewnej grupie etnolektów - mniej lub bardziej otwarcie aspirujących do samodzielności — nie udało się osiągnąć oficjalnie statusu języka: czy to regionalnego, czy to mniejszościowego, w końcu narodowego. Niepowodzenie procesów emacypacyjnych zwykle miało trzy przyczyny. Pierwsza z nich to brak elit mogących pokierować procesem językowego usamodzielniania. Drugą było niewystarczające poparcie szerszych mas społecznych, czasem wręcz zupełne niezainteresowanie próbami podejmowanymi przez elity forsujące projekt samodzielności językowej (por. casus etnolektu morawskiego czy etnolektu żmudzkiego). Trzecią przyczyną niepowodzenia dążeń emancypacyjnych był sprzeciw dominujących w określonym kraju kręgów politycznych, wspieranych zwykle przez państwowe instytucje naukowe. Podmioty te, odrzucając postulaty językowe strony mniejszościowej,

${ }^{2}$ Europejska karta języków regionalnych lub mniejszościowych, Dz.U. z 2009 r. Nr 137, poz. 1121, http://prawo.sejm.gov.pl/isap.nsf/DocDetails.xsp?id=WDU20091371121 [dostęp: 1.02.2018].

${ }^{3}$ Por. A. Spagińska-Pruszak, Sytuacja językowa w byłej Jugosławii, Łask 2005, s. 33-49. 
zwykle przywoływały argumenty natury polityczno-ustrojowej, społecznej, ekonomicznej i naukowej (wybuch niepokojów społecznych, możliwość rozpadu organizacji państwowej, nadmierne obciążenie budżetu centralnego, brak naukowych podstaw do uznania samodzielności określonego kodu itp.; na przykład $c a-$ sus etnolektu normandzkiego, korsykańskiego, prowansalskiego w Francji).

2. W takim właśnie kontekście - czyli w obliczu europejskiej „wiosny języków”, niegwarantującej jednak każdemu etnolektowi możliwości usamodzielnienia - należy umiejscowić główny obiekt zainteresowania niniejszej pracy, czyli etnolekt Górnoślązaków, od kilkunastu lat otwarcie aspirujący do językowej samodzielności. Próby emancypacji tego kodu nie są bowiem żadnym precedensowym wydarzeniem w świecie językoznawstwa, podobnie jak za ewenement nie może zostać uznany fakt, że mimo wielu prób usankcjonowania istnienia odrębnego języka śląskiego etnolekt ten $\mathrm{z}$ formalnoprawnego punktu widzenia wciąż ma status dialektu.

Stan badań nad współczesnym rozwojem etnolektu śląskiego nie jest zadowalający. Pomijając wspomnianą, bardzo cenną, monografię Artura Czesaka pod tytułem Wspótczesne teksty ślaskie na tle procesów językotwórczych $i$ standaryzacyjnych wspótczesnej Stowiańszczyzny, brakuje w polskiej literaturze naukowej opracowań stawiających sobie za zadanie w miarę pełne i całościowe omówienie przemian, jakim podlegało piśmiennictwo śląskie — i szerzej, śląszczyzna po przemianach ustrojowych z przełomu lat osiemdziesiątych i dziewięćdziesiątych XX wieku. Deficyt naukowej obserwacji wydaje się wynikać z dwóch przyczyn. Pierwszą z nich jest to, że duża część polskich naukowców traktuje próby emancypacji śląszczyzny $\mathrm{w}$ kategoriach procesu o czysto politycznym i ideologicznym wymiarze, forsowanym $w$ dodatku przez garstkę śląskich ekstremistów i radykałów ${ }^{4}$. Drugą przyczyną może być zwyczajna niewiedza o dynamice procesów językowych zachodzących na Górnym Śląsku, szczególnie zaś o skokowym rozwoju poliwalencji etnolektu śląskiego i stopniu jego kodyfikacji.

W niniejszej pracy, mając świadomość wszelkich nałożonych ograniczeń, zostanie przedstawiony skrócony zarys rozwoju etnolektu śląskiego w ostatniej dekadzie oraz szkic jego aktualnego położenia socjolingwistycznego. Wychodzi się z założenia, że emancypacji śląszczyzny nie można uznawać za proces mający czysto polityczny wymiar, a próba usamodzielnienia się tego kodu nie jest żadnym precedensowym wydarzeniem w świecie językoznawstwa. Nie ulega też wątpliwości, że dążenia do wyodrębnienia się śląszczyzny jako samodzielnego języka są procesem o bardzo ważnym znaczeniu dla polonistyki i - szerzej — slawistyki.

2.1. Etnolekt śląski, a precyzyjniej mówiąc ,język śląski”, to kod mający stosunkowo silne zaplecze demograficzne. Zgodnie z wynikami polskiego spisu powszechnego z 2011 roku ,język śląski” za język domowych kontaktów uznaje

${ }^{4}$ Por. np. M. Siuciak, Czy w najbliższym czasie powstanie język śląski?, „Poznańskie Studia Polonistyczne" 19, 2012, nr 2, s. 36. 
530 tys., a za język ojczysty - 140 tys. obywateli Polski ${ }^{5}$. Odnosząc się do tych wielkości, należy szczególną uwagę zwrócić na trzy fakty. Pierwszym z nich jest to, że Górnoślązaków cechuje wysoka świadomość językowej odrębności swojego kodu. Dowodzić tego może obecność zaledwie 467 deklaracji posługiwania się ,gwarą śląską" wobec przeszło półmilionowej rzeszy deklaracji posługiwania się ,językiem śląskim"6. Drugim istotnym faktem jest radykalny, niemal dziesięciokrotny, przyrost śląskich deklaracji językowych, zauważalny między spisem powszechnym z 2002 a 2011 roku (wzrost z 56 tys. do 530 tys.) $)^{7}$. Trzecim jest status ,języka śląskiego" jako największego niepolskiego języka kontaktów domowych [JKD] i języka ojczystego [JO] używanego na terenie Polski - według danych ze spisu powszechnego język śląski wyprzedza zarówno język kaszubski (108 tys. JKD i 14 tys. JO), język angielski (103 tys. JKD i 5 tys. JO), język niemiecki (96 tys. JKD i 58 tys. JO), język białoruski (26 tys. JKD i 17 tys. JO) oraz język ukraiński (24 tys. JKD i 28 tys. JO) ${ }^{8}$.

Choć działania mające na celu emancypację śląszczyzny trwają już od kilkunastu lat, dopiero w ostatniej dekadzie zostały zintensyfikowane i sformalizowane. Dowodzi tego fakt, że między 2007 a 2017 rokiem czterokrotnie procedowano nowelizację ustawy o mniejszościach narodowych i etnicznych oraz o języku regionalnym w celu nadania śląszczyźnie statusu polskiego języka regionalnego bądź mniejszościowego. Za każdym razem projekty nowelizacji były odrzucane na różnym etapie prac sejmowych. Najnowszy, piąty projekt nowelizacji ustawy, złożony zimą 2018 roku do Sejmu przez partię .Nowoczesna, został odrzucony w czerwcu 2019 roku$^{9}$.

2.2. Ostatnie dziesięć lat to okres, w którym etnolekt śląski wyraźnie rozwinął swoje możliwości poliwanencji oraz wyraźnie podniósł swoje społeczne wartościowanie i status komunikacyjny. Jak wiadomo, mowa śląska już od kilkunastu przynajmniej lat wykracza poza przestrzeń komunikacji nieoficjalnej i prywatnej, będąc obecna w różnego rodzaju lokalnych mediach (Radio Piekary, TV Silesia, Jaskółka Śląska). W ostatniej jednak dekadzie zaczęła być traktowana jako medium komunikacji o znaczącym potencjale marketingowym. Świadczy o tym używanie śląszczyzny w licznych kampaniach reklamowych, które prowadzone są nie tylko przez lokalne, śląskie przedsiębiorstwa, lecz także koncerny o ogólnopolskim czy nawet światowym zasięgu. Wymienić tu można między innymi kampanie reklamo-

${ }^{5}$ Struktura narodowo-etniczna, językowa i wyznaniowa ludności Polski - NSP 2011, Główny Urząd Statystyczny, Warszawa 2015, s. 70, https://stat.gov.pl/spisy-powszechne/nsp-2011/nsp-2011 -wyniki/struktura-narodowo-etniczna-jezykowa-i-wyznaniowa-ludnosci-polski-nsp-2011,22,1.html [dostęp: 1.09.2018].

${ }^{6}$ Ibidem, s. 173.

7 Ibidem, s. 72.

${ }^{8}$ Ibidem, s. 70, 82.

${ }^{9}$ M. Zasada, Śląski język regionalny: piąte podejście. Dzisiaj do Sejmu trafi projekt ustawy o śląskim języku regionalnym, „Dziennik Zachodni” 11.01.2018, https://plus.dziennikzachodni.pl/ wiadomosci/a/slaski-jezyk-regionalny-piate-podejscie-dzisiaj-do-sejmu-trafi-projekt-ustawy-o-slas kim-jezyku-regionanym,12837358 [dostęp: 1.09.2018]. 
we Volkswagena, Coca-Coli, Samsunga, Credit Agricole, Hochlandu, USP Zdrowie (Ibuprom), AXA Direct (Liberty), Canal+ (Telewizja N), Heineken (Żywiec), Agora (kina Helios). Szczególnie dużo uwagi śląskiej mowie poświęca polski oddział Samsunga - wskutek tego wybrane modele smartfonów marki Samsung już od 2015 roku mają wbudowane śląskojęzyczne menu. Na marginesie można wspomnieć, że język śląski wykorzystał w 2016 roku Wrocławski Uniwersytet Przyrodniczy na ulicznych billboardach reklamowych, zachęcających górnośląską młodzież do studiowania na wrocławskiej uczelni ${ }^{10}$.

Ostatnia dekada to również okres ekspansji śląskiej mowy w obszar mediów elektronicznych. W 2008 roku powstała śląska wersja Wikipedii, licząca obecnie (na październik 2019 roku) ponad 53 tysiące haseł. Od 2016 roku działa śląskojęzyczna wersja portalu społecznościowego Facebook, a od 2018 roku funkcjonuje informacyjny portal internetowy Wachtyrz.eu, na którym połowa tekstów publikowana jest po śląsku. Od grudnia 2018 roku funkcjonuje też portal Silling.org, zawierający ogólnodostępny korpus języka śląskiego oraz automatyczny tłumacz polsko-śląski oraz śląsko-polski.

2.3. W ostatnim dziesięcioleciu można zauważyć dynamiczny rozwój piśmiennictwa śląskiego, które bezsprzecznie wykroczyło poza typowe kanony literatury dialektalnej. W okresie tym ukazało się kilkanaście powieści i zbiorów opowiadań napisanych po śląsku, wydrukowano kilka tomów śląskich jednoaktówek, zbiorów poezji i bajek. Opublikowano kilka obszernych przekładów klasyki światowej prozy i poezji, ukazały się też pisane po śląsku dzieła eseistyczne. Warto dodać, że najpopularniejsze śląskojęzyczne pozycje wydawane były także pod postacią audiobooków i e-booków.

Wśród prozatorskich osiągnięć śląszczyzny w ostatniej dekadzie szczególnie należy wyróżnić cykl powieści epistolograficznych Alojzego Lyski Duchy woj$n y^{11}$. Istotne miejsce zajmuje tu ciesząca się dużą poczytnością tetralogia detektywistyczna Marcina Melona, poświęcona przygodom Komisarza Hanusika ${ }^{12}$. Za bardzo udany należy uznać zbiór opowiadań Rafała Szymy pod tytułem Lean$\operatorname{derka}^{13}$, który tematycznie wybiega poza realia Śląska i typową śląską tematykę. Śląska eseistyka i literatura o charakterze popularnonaukowym nie doczekała się większej liczby publikacji. W ostatniej dekadzie ukazał się jedynie zbiór esejów

${ }^{10}$ Zob. np. A. Hadasz, Reklamy po Ślasku: Światowe koncerny, ale i szkoły czy uczelnie zabiegaja o Ślazaków, „Dziennik Zachodni” 23.07.2017, https://dziennikzachodni.pl/reklamy-po-slasku-swiatowe-koncerny-ale-i-szkoly-czy-uczelnie-zabiegaja-o-slazakow/ar/12296565 [dostęp: 1.09.2018].

11 A. Lysko, Duchy wojny. W koszarach po szczytami Alp, Katowice 2008; idem, Duchy wojny. W bunkrach Watu Atlantyckiego, Katowice 2009; idem, Duchy wojny. W okopach frontu wschodniego, Katowice 2010; idem, Duchy wojny. W objęciach śmierci, Cieszyn 2011; idem, Duchy wojny. Wudręce nadziei, Cieszyn 2014; idem, Duchy wojny. W przekleństwie kalectwa, Cieszyn 2016; idem, Duchy wojny. W sieroctwie bez skargi, Cieszyn 2017.

12 M. Melon, Komisōrz Hanusik, Kotōrz Mały 2014; idem, Komisōrz Hanusik. We tajnyj shużbie ślōnskij nacyje, Kotōrz Mały 2015; idem, Komisōrz Hanusik i Sznupok, Kotōrz Mały 2016; idem, Komisōrz Hanusik. Umrzik we szranku, Kotōrz Mały 2017.

${ }^{13}$ R. Szyma, Leanderka. 5 ôsprŏwek pō naszymu, Kotōrz Mały 2017. 
Listy z Rzymu Zbigniewa Kadłubka ${ }^{14}$ oraz obszerna, kilkusetstronnicowa, Filozofja po ślōnsku Marcina Kika ${ }^{15}$.

Znaczący jest za to dorobek śląskich thumaczy. Pośród dokonań translatorycznych najważniejsze miejsce bez wątpienia zajmuje kompletny (oparty na Biblii Jakuba Wujka) śląski przekład Nowego Testamentu, dokonany w 2017 roku przez Gabriela Tobora ${ }^{16}$. Duże znaczenie dla rozwoju poliwalencji śląszczyzny miały dokonania translatoryczne Mirosława Syniawy, który w 2014 roku opublikował obszerną antologię Dante a inksi ${ }^{17}$, zawierającą przekłady utworów między innymi Horacego, Dantego, Angelusa Silesiusa, Williama Blake'a, Josepha von Eichendorffa i Siergieja Jesienina. Ten sam autor dwa lata później opublikował przekład tomu poezji najsłynniejszego szkockiego poety Roberta Burnsa - Spōmnijcie se Tamowã klaczk $\tilde{a}^{18}$. Wśród dokonań translatorycznych istotne miejsce zajmuje przekład antycznej tragedii Ajschylosa - Prōmytojs przibity ${ }^{19}$ (pol. Prometeusz w okowach), którą na podstawie starogreckiego oryginału przygotował Zbigniew Kadłubek, oraz zbiór aforyzmów Franza Kafki przethumaczony przez Jerzego Ciurloka ${ }^{20}$. Ostatecznie należy wspomnieć o działalności translatorycznej Grzegorza Kulika. Bytomski tłumacz w 2017 roku opublikował przekład opowiadania Charlesa Dickensa Godniǒ pieśń ${ }^{21}$ (pol. Opowieść wigilijna), a w 2018 roku przekład powieści Drach Szczepana Twardocha ${ }^{22}$ oraz thumaczenie klasycznego dzieła Antoine'a de Saint-Exupéry'ego Mały Princ (pol. Mały Książę) ${ }^{23}$.

2.4. Śląski etnolekt nie został do tej pory w pełni skodyfikowany, co do pewnego stopnia nie może zaskakiwać, gdy w grę wchodzi kod oficjalnie uznawany za dialekt i pozbawiony jakiegokolwiek realnego, administracyjnego wsparcia. W największym stopniu udało się uregulować śląską ortografię. Choć w praktyce można spotkać kilka rodzajów śląskiego zapisu, to pisownia „ślabikorzowa”, która została opracowana w 2009 roku przez zespół pod przewodnictwem Jolanty Tambor, upowszechniła się na Górnym Śląsku i jest bez wątpienia najczęściej stosowanym sposobem zapisu tekstów śląskich. Pisownia ta używana jest przez pisarzy i tłumaczy współpracujących z największym śląskojęzycznym wydawnictwem Silesia Progress (Marcin Melon, Rafał Szyma, Mirosław Syniawa, Jerzy Ciurlok, Grzegorz Kulik), ale też przez innych twórców, w tym Szczepana Twar-

${ }^{14}$ Z. Kadłubek, Listy z Rzymu, Katowice 2008.

${ }^{15}$ M. Kik, Filozofjo po ślōnsku. Czyli heft do historje filozofje dziadka Kika, Kotōrz Mały 2015.

16 Nowy Testamynt po ślonsku, przeł. G. Tobor, Radzionków 2017.

17 Dante i inksi, przeł. M Syniawa, Kotōrz Mały 2014.

18 R. Burns, Spōmnijcie se Tamowã klaczkã. Remember Tam O'Shanter's mare, przeł. M. Syniawa, Kotōrz Mały 2016.

19 Ajschylos, Prōmytojs przibity, przeł. Z. Kadłubek, Kotōrz Mały 2013.

20 Ślōnski Kafka, przeł. J. Ciurlok, Kraków 2016.

${ }^{21}$ K. Dickens, Godniǒ pieśń, przeł. G. Kulik, Kotōrz Mały 2017.

22 S. Twardoch, Drach. Edycyjó ślōnskó, przeł. G. Kulik, Kraków 2018.

${ }^{23}$ A. de Saint-Exupéry, Mały Princ, przeł. G. Kulik, Poznań 2018. 
docha i Alojzego Lyskę. Pisownia ,ślabikorzowa” stosowana jest także w śląskojęzycznych tekstach publikowanych na portalu informacyjnym Wachtyrz.eu.

Choć w 2017 roku ukazała się Gramatyka gwary górnośląskiej Jana Dren$\mathrm{dy}^{24}$, wcześniej zaś opublikowano liczne śląskie elementarze, podręczniki, samouczki i rozmówki z komponentem gramatycznym (głównie fleksyjnym) ${ }^{25}$, trudno mówić o istnieniu eksplicytnej, powszechnie akceptowanej, śląskiej normy gramatycznej. Podobnie jest z normą leksykalną — choć na rynku można znaleźć stosunkowo dużo śląskich słowników i słowniczków (w tym dwa wyróżniające się obszernością deskryptywne słowniki polsko-śląskie i śląsko-polskie Bogdana Kallusa i Andrzeja Rocznioka ${ }^{26}$ ), nie dowodzi to istnienia ustabilizowanej śląskiej normy leksykalnej. Na marginesie trzeba podkreślić, że zdecydowana większość istniejących publikacji gramatyczno-leksykograficznych ma charakter amatorski i cechuje się niskim poziomem merytorycznym. Takie publikacje są jednak dowodem na istnienie zaawansowanych prób kodyfikacji śląszczyzny.

3. Reasumując, można stwierdzić, że proces emancypacji śląszczyzny to problem badawczy, którego polonistyka — i szerzej slawistyka — nie może ignorować. O jego doniosłości decyduje socjolingwistyczny potencjał śląskiego etnolektu oraz możliwe konsekwencje usamodzielnienia się tegoż kodu. Mowa o medium komunikacji, które odznacza się stosunkowo dużym zapleczem demograficznym, wyjątkową dynamiką rozwoju poliwalencji oraz funkcjonowaniem w nowoczesnych mediach elektronicznych. Nie można też zapominać, że jego użytkowników cechuje niemal powszechna świadomość językowej odrębności, a większość śląskojęzycznych twórców — stosunkowo niska średnia wieku.

Hipotetyczne formalnoprawne usamodzielnienie się śląszczyzny i podniesienie jej do rangi języka regionalnego jest oczywiście uzależnione od woli dominujących w Polsce sił politycznych oraz społecznej atmosfery panującej w kraju. Na razie trudno odnaleźć przesłanki świadczące o możliwości rychłego oficjalnego uznania istnienia języka śląskiego. Warto jednak zauważyć, że choć oficjalny status śląszczyzny rzutuje w istotny sposób na jej rozwój, dalsze istnienie tego kodu jest uzależnione przede wszystkim od woli samych jego użytkowników. To Górnoślązacy, wybierając narzędzie swojej codziennej komunikacji, zadecydują, czy ich mowa na dłużej zachowa status żywego medium komunikacji, czy też odejdzie do historii językoznawstwa jako kolejny martwy etnolekt, funkcjonujący niegdyś na obszarze Polski.

${ }^{24}$ J. Drenda, Gramatyka gwary górnośląskyj [regiónu katowicko-bytómskygo], nakład autora, Siemianowice Śląskie 2017.

${ }^{25}$ Do najbardziej znanych zaliczyć można trzy pozycje: R. Adamus et al., Gōrnoślōnski ślabikǒrz, Chorzów 2010; D. Dyrda, Rýchtig gryfno godka (porěncznik ślůnskiej godki), Lędziny [b.d.w.]; M. Szołtysek, Rozmówki ślaskie. Podręcznik do nauki ślaskiej godki, Rybnik 2008.

${ }^{26}$ B. Kallus, Stownik gōrnoślōnskij gǒdki. Stownik polsko-górnoślaski. Stownik górnoślasko-polski, Chorzów 2015; A. Roczniok, Stownik polsko-śląski. Zbornik polsko-ślůnski, t. 1-3, Zabrze 2008-2015. 


\section{Bibliografia}

Czesak A., Wspótczesne teksty śląskie na tle procesów językotwórczych i standaryzacyjnych wspótczesnej słowiańszczyzny, Kraków 2015.

Jaroszewicz H., Język ślaski - dlaczego rozmowa jest tak trudna?, „Fabryka Silesia” 2013, nr 2 (4).

Lubaś W., Polszczyzna śląska - pomocniczy język regionalny, [w:] idem, Studia socjolingwistyczne, Opole 2013.

Michna E., Odrębność językowa małych grup etnicznych i jej rola w procesach walki o uznanie oraz polityce tożsamości. Analiza porównawcza sytuacji Rusinów Karpackich i Ślazaków, „Studia Humanistyczne AGH” 13, 2014, nr 3.

Siuciak M., Czy w najbliższym czasie powstanie język śląski?, „Poznańskie Studia Polonistyczne. Seria Językoznawcza" 19, 2012, nr 2.

Skudrzykowa A. et al., Gwara ślaska - świadectwo kultury, narzędzie komunikacji, Katowice 2011. Spagińska-Pruszak A., Sytuacja językowa w byłej Jugosławii, Łask 2005.

Tambor J., Mowa Górnośląaków oraz ich świadomość językowa i etniczna, Katowice 2008.

Tambor J., Propozycje kodyfikacji ortograficznej ślaszczyzny, „Socjolingwistyka” 22-23, 2009.

Wyderka B., O rozwoju polskich dialektów, „Poznańskie Studia Polonistyczne” 21 (41), 2014, z. 2.

\section{Źródła internetowe}

Europejska karta języków regionalnych lub mniejszościowych, Dz.U. z 2009 r. Nr 137, poz. 1121, http://prawo.sejm.gov.pl/isap.nsf/DocDetails.xsp?id=WDU20091371121 [dostęp: 1.02.2018].

Hadasz A., Reklamy po Ślasku: Światowe koncerny, ale i szkoty czy uczelnie zabiegaja o Ślazaków, „Dziennik Zachodni” 23.07.2017, https://dziennikzachodni.pl/reklamy-po-slasku-swiatowekoncerny-ale-i-szkoly-czy-uczelnie-zabiegaja-o-slazakow/ar/12296565 [dostęp: 1.09.2018].

Struktura narodowo-etniczna, językowa i wyznaniowa ludności Polski - NSP 2011, Główny Urząd Statystyczny 2015, http://stat.gov.pl/spisy-powszechne/nsp-2011/nsp-2011-wyniki/struktura-narodowo-etniczna-jezykowa-i-wyznaniowa-ludnosci-polski-nsp-2011,22,1.htm [dostęp: 1.09.2018].

Zasada M., Śląski język regionalny: piąte podejście. Dzisiaj do Sejmu trafi projekt ustawy o śląskim języku regionalnym, „Dziennik Zachodni” 11.01.2018, https://plus.dziennikzachodni.pl/wiadomosci/a/slaski-jezyk-regionalny-piate-podejscie-dzisiaj-do-sejmu-trafi-projekt-ustawy-o-sl askim-jezyku-regionanym,12837358 [dostęp: 1.09.2018].

\section{The contemporary development of the Silesian ethnolect in comparison with the linguistic processes of emancipation in Europe}

\section{Summary}

For more than ten years the Silesian ethnolect has been rapidly developing. During this time, its polyvalence, the level of codification and the scope of its use have been radically expanded. This code is used by a relatively big number of speakers $(530,000)$ who consider it a separate language and not a local dialect of Polish. The legal status of the Silesian ethnolect depends on the linguistic policy implemented in modern Poland. At present, however, there is no political will to elevate this code to the status of an independent language.

Keywords: standardisation, language policy, Silesian ethnolect, the Polish language, regional language

Slavica Wratislaviensia 171, 2020

(C) for this edition by CNS 


\section{Suvremen razvoj šleskog varijeteta u kontekstu jezičnih emancipacijskih procesa u Europi}

\section{Rezime}

U posljednih dvadeset godina primjećuje se dinamičan i intenzivan razvoj šleskog jezičnog varijeteta. U ovom vremenskom razdoblju radikalno se povećala polivalentnost šleskog idioma, stupanj njegove kodifikacije, znatno se takoder proširilo komunikacijsko i stilsko područje njegove upotrebe. Šleski jezični varijetet karakterizira prilično veliki broj izvornih govornika (530.000.), koji - što valja napomenuti - ne smatraju ga jednim od poljskih dijalekata već zasebnim jezikom. Pravni položaj šleskog jezičnog varijeteta ovisi naravno o obliku državne, jezične politike. Čini se ipak da u ovom trenutku nedostaje u Poljskoj političke volje da se šleski jezični varijetet prizna zasebnim jezikom. jezik

Ključne riječi: standardizacija, jezična politika, šleski jezični varijetet, poljski jezik, regionalni 